\title{
Influence of Prior-Austenite Grain Structure on the Mechanical Properties of Ultrafine Elongated Grain Structure Steel Processed by Warm Tempforming
}

\author{
Yuuji KIMURA* and Tadanobu INOUE \\ National Institute for Materials Science, 1-2-1 Sengen, Tsukuba, Ibaraki, 305-0047 Japan.
}

(Received on February 10, 2015; accepted on March 31, 2015)

\begin{abstract}
$0.4 \% \mathrm{C}-2 \% \mathrm{Si}-1 \% \mathrm{Cr}-1 \% \mathrm{Mo}$ steels with different austenite grain structures were quenched and tempered at $773 \mathrm{~K}$ and deformed by multi-pass caliber rolling with a rolling reduction of $78 \%$ (i.e. warm tempforming, (WTF)). The microstructures, in addition to the tensile and Charpy impact properties of the warm tempformed (TF) steels, were investigated in relation to the prior-austenite grain (PAG) structures. The TF samples demonstrated hierarchical microstructures consisting of "packet bands" and "ultrafine elongated grains (UFEGs)". The PAG structure had little influence on the transverse grain size, grain shape, $<110>/ /$ rolling direction (RD) fiber texture, and carbide particle distribution in the UFEG structure, while the size of the packet bands decreased as the PAG size decreased. The PAG size had little influence on the strength of the TF sample. However, the effect of the WTF on the tensile ductility and toughness was enhanced as the PAG size decreased. It was demonstrated that as the PAG size decreased, the inverse temperature dependence of impact toughness (resulting from delamination) became significant at lower temperatures. The delamination toughening mechanism was discussed in relation to the UFEG and packet band structures.
\end{abstract}

KEY WORDS: thermomechanical treatment; martensitic steel; strength; toughness; ultrafine grained microstructure.

\section{Introduction}

We have recently developed a thermomechanical treatment, in which tempered martensite is deformed (tempforming $^{1)}$ ) at an elevated temperature. This is known as warm tempforming (WTF). ${ }^{2-6)}$ When the WTF was applied to medium-carbon low-alloy steels, using multi-pass caliber rolling with a rolling reduction of $78 \%$ at a temperature of $773 \mathrm{~K}$, ultrafine elongated grain (UFEG) structures with strong $<110>/ /$ rolling direction (RD) fiber textures were formed and an excellent combination of yield strength and notch toughness was achieved. ${ }^{2-6)}$ For example, a $0.4 \% \mathrm{C}-2 \% \mathrm{Si}-1 \% \mathrm{Cr}-1 \% \mathrm{Mo}$ steel with an UFEG structure had an average yield strength $\left(\sigma_{y}\right)$ of $1.84 \mathrm{GPa}$ and an average Charpy V-notch absorbed energy $(v E)$ of $226 \mathrm{~J}$ at room temperature. ${ }^{2,3)}$ Furthermore, the steels with the UFEG structures were found to exhibit an inverse temperature dependence of toughness; the $v E$ of the steels with the UFEG structures increased as the temperature decreased. This is in contrast to conventional ultra-high-strength lowalloy steels which exhibit a ductile-to-brittle transition (DBT).

The enhancement of the toughness for the steels with the UFEG structures is induced as a result of the occurrence of

\footnotetext{
* Corresponding author: E-mail: KIMURA.Yuuji@nims.go.jp DOI: http://dx.doi.org/10.2355/isijinternational.ISIJINT-2015-081
}

delaminations, in which cracks branch and propagate in the longitudinal direction of the notched bars. This is known as delamination toughening. ${ }^{2-6)} \mathrm{We}$ clarified that the dominant factors responsible for delamination toughening were the transverse grain size, grain shape, $<110>/ / \mathrm{RD}$ fiber texture, and carbide particle distribution in the UFEG structure. $\left.{ }^{6}\right)$ However, a question still arises as to whether the prior-austenite grain (PAG) structure can influence the delamination toughening or not. This is because it was observed that the evolution of the UFEG structure was dependent on variations in the crystallographic orientation and the geometric arrangement of blocks and/or packets in the tempered martensite. ${ }^{3)}$ It is well-known that the austenite grain size can influence the size of the blocks and packets. ${ }^{7-9)}$ The strength and toughness of martensitic steels can be related to the block and packet structures. ${ }^{7-13)}$

The aim of the present study is to investigate the influence of the PAG structure on the evolution of the UFEG structure, in addition to the tensile and Charpy V-notch impact properties of the warm tempformed steel. The WTF process using multi-pass caliber rolling at a temperature of $773 \mathrm{~K}$ with a rolling reduction of $78 \%$ was applied to $0.4 \% \mathrm{C}-2 \% \mathrm{Si}-1 \% \mathrm{Cr}-1 \% \mathrm{Mo}$ steels with different PAG structures. The delamination toughening of the steel with an UFEG structure was also discussed in relation to the PAG structure. 


\section{Experimental}

\subsection{Material and Thermomechanical Treatment}

$100 \mathrm{~kg}$ ingots were prepared by vacuum melting and casting. They were subsequently homogenized at $1473 \mathrm{~K}$, and hot-rolled into plates with a thickness of $4 \mathrm{~cm}$. Table 1 lists the chemical compositions of the $0.4 \% \mathrm{C}-2 \% \mathrm{Si}-1 \% \mathrm{Cr}-$ $1 \%$ Mo steels. Prior to the WTF process, blocks measuring $12 \times 4 \times 4 \mathrm{~cm}$ were cut from the hot-rolled plates and subjected to three different thermomechanical treatments. This was performed in order to vary the austenite grain structure:

(1) The blocks were solution-treated at $1473 \mathrm{~K}$ for $1 \mathrm{~h}$ to reduce undissolved carbides, and subjected to multipass hot caliber rolling into squared bars with a crosssectional area of $9 \mathrm{~cm}^{2}$, followed by water quenching (THT 1).

(2) Some of the quenched bars processed by THT 1 were subsequently austenitized at $1373 \mathrm{~K}$ for $1 \mathrm{~h}$, followed by water quenching (THT 2).

(3) The blocks were heated to $1473 \mathrm{~K}$, and subjected to multi-pass hot caliber rolling into squared bars with a cross-sectional area of $9 \mathrm{~cm}^{2}$. They were subsequently solution-treated at $1473 \mathrm{~K}$ for $1 \mathrm{~h}$, followed by water quenching (THT 3).

The quenched bars which were processed through treatments THT 1-3 were tempered at $773 \mathrm{~K}$ for $1 \mathrm{~h}$ and subsequently subjected to WTF using multi-pass caliber rolling with a rolling reduction of $78 \%$ (=equivalent strain of 1.7 ). This produced squared bars with a cross-sectional area of 2 $\mathrm{cm}^{2}$, which were subsequently air cooled (the TF samples). The total number of rolling passes was 9 for steel $\mathrm{A}^{2,3)}$ and 13 for steels $\mathrm{B}$ and $\mathrm{C}$, ${ }^{6}$ respectively. During rolling, the samples were held in a furnace for 5 min following every three or four passes. Some of the quenched bars which were processed through THT 1-3 were tempered at $773 \mathrm{~K}$ for $1 \mathrm{~h}$ and subsequently air cooled (the QT samples).

The principal axes of the squared bar were defined as follows: the axis that was coincident with the rolling direction was defined as the RD, the axis which was coincident with the direction of the main working force at the final pass was defined as the ND, and the axis which was normal to the RD and ND was defined as the TD.

\subsection{Microstructural Characterization and Mechanical Testing}

The microstructures were observed by optical microscopy, scanning electron microscopy (SEM), and transmission electron microscopy (TEM). The electron backscatter diffraction pattern (EBSP) analysis was performed using a SEM which was equipped with a field emission gun (FESEM). The step size was 50 or $200 \mathrm{~nm}$. The conditions for the FE-SEM/EBSP analysis are described in detail elsewhere. $^{3)}$ The integrated intensities of the (110) XRD peaks
$\left(\mathrm{I}_{\mathrm{m}}\right)$ were measured on the RD planes for the TF samples. For the standard samples, the ratio of $\mathrm{I}_{\mathrm{m}}$ to the integrated intensity of the (110) XRD peak $\left(\mathrm{I}_{\mathrm{s}}\right)$ was measured to evaluate the development of the $<110>/ /$ RD fiber textures. For each sample, the sizes of 500-600 carbide particles were measured from 2-3 TEM-bright field images.

Tensile tests were conducted on the JIS Z 2201-14A specimens (with a diameter of $6 \mathrm{~mm}$, and machined in the RD (JIS-14A specimens)), at a crosshead speed of 0.85 $\mathrm{mm} / \mathrm{min}$. The gauge length of the JIS-14A specimens was $30 \mathrm{~mm}$. A $\sigma_{y}$ of $0.2 \%$ offset was reported. The true fracture stress $\left(\sigma_{F}\right)$ was calculated by dividing the load at failure by the minimum cross-sectional area of the ruptured specimen. Charpy impact tests were performed for the full-size $2 \mathrm{~mm}$ $\mathrm{V}$-notch specimens that were machined in the RD. The striking direction (SD) of the impact tests had an angle of $\sim 45^{\circ}$ to the TD and ND.

\section{Results}

\subsection{Microstructures}

Figure 1 demonstrates the microstructures of the QT samples. The microstructures of the matrix prior to the WTF process were characterized as tempered martensitic structures where the PAGs were subdivided into packets, as indicated by the arrows. The packet size was refined as the PAG size decreased. The average intercept length $\left(I L_{A V}\right)$ for the packets $\left(I L_{P}\right)$ was measured to be $14 \mu \mathrm{m}$ for steel A (which was subjected to THT 1) and was $191 \mu \mathrm{m}$ for steel C (which was subjected to THT 3). These packets were further subdivided into fine blocks (Figs. 1(d)-1(f)); the boundaries of the blocks were defined as grain boundaries with a misorientation angle $(\theta)$ of $10^{\circ}$ or greater. ${ }^{3)}$ For example, the $I L_{A V}$ for the blocks $\left(I L_{B}\right)$ was measured to be $0.49 \mu \mathrm{m}$ for steel $\mathrm{A}^{3}$ ) and was $0.60 \mu \mathrm{m}$ for steel $\mathrm{C}$ (which was subjected to THT 3). The block structure tended to be slightly finer with decreasing the PAG size. Additionally, the coarse PAGs which were elongated along the RD were partially observed within steel $\mathrm{C}$ (which was subjected to THT 1) (Fig. 1(b)). Such elongated grains are most likely to be deformed, un-recrystallized grains formed during the hot caliber-rolling. Table 2 summarizes the $I L_{A V}$ of the PAGs along the transverse direction $\left(I L_{\gamma}\right)$, and the area fraction of the equiaxed PAGs. The $I L_{\gamma}$ varied between approximately 50 and $600 \mu \mathrm{m}$, depending on the steels and the conditions of THT 1-3. Although the $I L_{\gamma}$ for the equiaxed (recrystallized) PAGs was measured to be approximately $50 \mu \mathrm{m}$ for all the steels processed through THT1, the $I L_{\gamma}$ varied in the range of 47 to $92 \mu \mathrm{m}$, depending on the fraction of the coarse, elongated (un-recrystallized) grains (e.g. see Fig. $1(\mathrm{~b})$ ).

The dynamic recrystallized grain size is independent of the initial austenite grain size and the deformation strain.

Table 1. Chemical compositions of the steels used (mass\%).

\begin{tabular}{cccccccccccc}
\hline Steels & C & Si & Mn & Cr & Mo & Al & P & S & O & N \\
\hline A & 0.39 & 1.98 & 0.21 & 1.04 & 1.05 & 0.041 & $<0.001$ & $<0.001$ & $<0.005$ & 0.002 \\
B & 0.41 & 1.98 & 0.20 & 1.01 & 1.00 & 0.022 & 0.001 & $<0.001$ & 0.001 & 0.0008 \\
C & 0.43 & 1.97 & 0.20 & 1.02 & 0.96 & 0.021 & 0.002 & 0.001 & 0.0007 & 0.002 \\
\hline
\end{tabular}



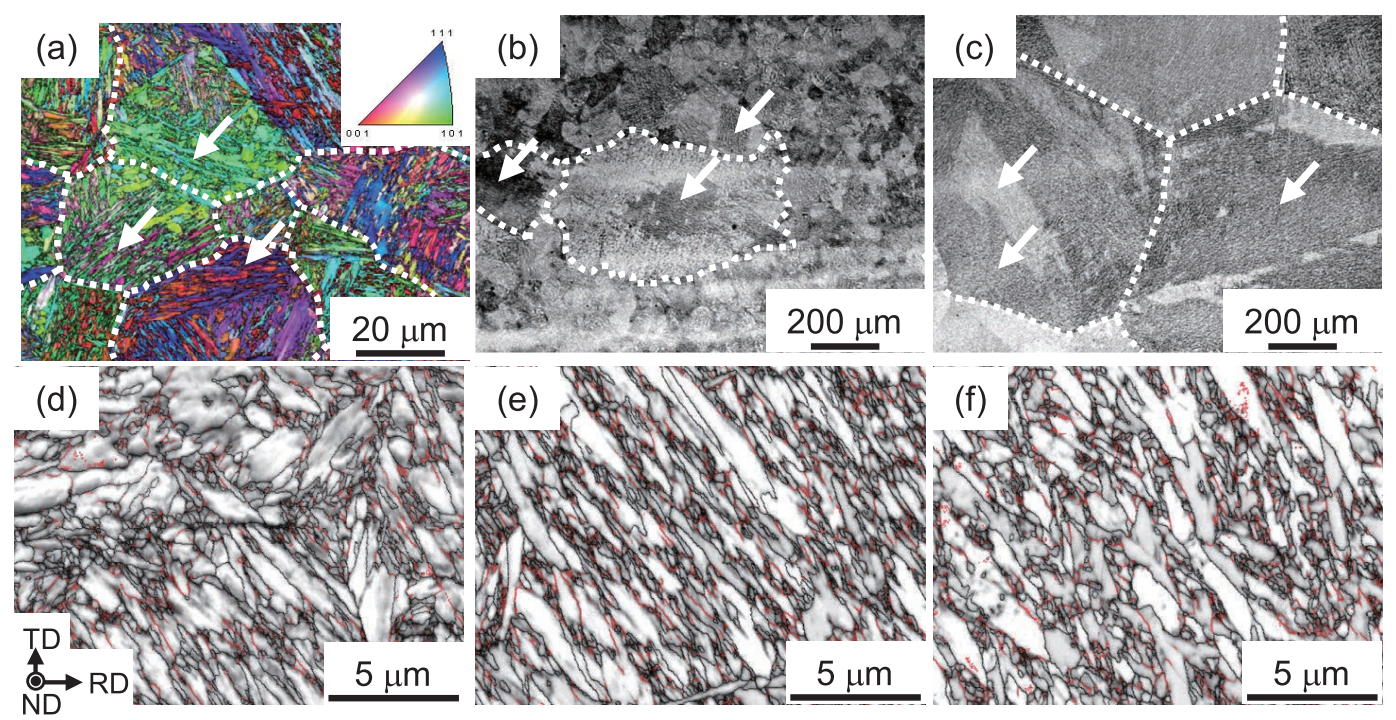

Fig. 1. Microstructures of the QT samples: steel A processed by THT 1((a), (d)), steel C processed by THT 1((b), (e)) and by THT $3((\mathrm{c}),(\mathrm{f}))$. The dash lines and arrows denote the prior-austenite grain (PAG) boundaries and packets, respectively, in the inverse pole figure (IPF) map (a) and optical micrographs ((b), (c)). The black and red lines in the image quality (IQ) maps ((d)-(f)) represent boundaries with a misorientation angle of $\theta \geq 10^{\circ}$ and a low angle boundary with a misorientation angle of $2 \leq \theta<10^{\circ}$, respectively.

Table 2. Average intercept length of the prior-austenite grains (PAGs) along the transverse direction $\left(I L_{\gamma}\right)$ and the area fraction of the equiaxed PAGs $\left(\mathrm{F}_{\mathrm{A}}\right)$ in steels A-C which were processed by thermomechanical treatments 1-3 (THT 1-3).

\begin{tabular}{clcc}
\hline THT & \multicolumn{1}{c}{ Steels } & $I L_{\gamma} / \mu \mathrm{m}$ & $\mathrm{F}_{\mathrm{A}}(\%)$ \\
\hline THT 1 & Steel A,3) & 47 & Almost 100 \\
& Steel B & 72 & 90 \\
& Steel C & 92 & 75 \\
THT 2 & Steel C & 255 & - \\
THT 3 & Steel B & 400 & - \\
& Steel C & 595 & - \\
\hline
\end{tabular}

It is only determined by the deformation conditions (i.e. the Zener-Hollomon parameter), which is a function of the strain rate and deformation temperature. ${ }^{14)}$ Furthermore, the initial austenite grain size influences the kinetics of recrystallization; with the same deformation conditions, the recrystallized fraction increases as the initial grain size decreases. Hence, the area fraction of the equiaxed PAGs produced from THT 1 can be explained in terms of the initial austenite grain size. Actually, the $I L_{\gamma}$ of steel B $(=400$ $\mu \mathrm{m})$ is smaller than that of steel C $(=595 \mu \mathrm{m})$ for the same THT 3 conditions. The smallest austenite grain size was also observed in steel $\mathrm{A}$, when the steels were austenitized at $1473 \mathrm{~K}$ for $1 \mathrm{~h}$. This difference in the austenite grain growth behavior may be influenced by factors such as minor alloying elements and impurities; however, it was beyond the scope of this study to clarify it.

Figure 2 shows the microstructures of the TF samples. Band-like structures are observed, as indicated by the arrows in Figs. 2(a) and 2(d). By comparing the microstructures of the QT and TF samples, such band-like structures are considered to evolve through the extension of packets in the $\mathrm{RD}$, and will henceforth be referred to as "packet bands". The $I L_{A V}$ for the packet band width $\left(I L_{P B}\right)$ were measured to be $13 \mu \mathrm{m}$ for steel $\mathrm{C}$ (which was subjected to THT 1), and $95 \mu \mathrm{m}$ for steel C (which was subjected to THT 3), respectively. The packet band width is reduced as the PAG size decreases. The UFEG structures evolve inside the packet bands (as shown in Figs. 2(b) and 2(e)). Here the grain boundaries with a $\theta$ of $15^{\circ}$ or over were defined as high angle grain boundaries (HABs). The $I L_{A V}$ for the HABs $\left(I L_{U F E G}\right)$ in the transverse and longitudinal directions in the UFEG structures for steel C processed by THT 1were measured to be 0.28 and $0.70 \mu \mathrm{m}$, respectively, and they were measured to be 0.31 and $0.65 \mu \mathrm{m}$ for steel $\mathrm{C}$ processed by THT 3 . There are no significant differences in the grain size and grain shape of the UFEG structures, although the packet band size varies depending on the PAG size. The TEM observation also reveals that these samples have a very similar distribution of spheroidized carbide particles (Figs. 2(c) and 2(f)). These carbides were identified as cementite, in which substitutional elements such as $\mathrm{Cr}, \mathrm{Mn}$, and $\mathrm{Mo}$ are dissolved. ${ }^{6}$ Figure 3 shows the inverse pole figure (IPF) map for the SD on the ND plane of a TF sample. The (110) and (100) pole figures are also shown. A strong $<110>/ / R D$ fiber texture was confirmed to develop. It must be emphasized that the crystallographic orientation and geometric arrangement of the UFEGs are different for each packet band (as indicated by arrows). The dash arrows indicate the UFEGs that appear to be irregularly bent; these UFEGs are suggested to evolve through the deformation of blocks whose long axes are aligned at high angles to the RD. Such features were commonly observed in all the TF samples. Ueji et al. ${ }^{15)}$ reported that there were three kinds of typical microstructures when a lath martensite was cold-worked with a plate rolling mill; 1) the lamellar dislocation cell (LDC) structure mainly composed of the lamellar boundaries elongated to the $\mathrm{RD}, 2$ ) the irregularly bent lamella (IBL) structure, and 3) the kinked lath (KL) structure, in which the martensite lath is kinked by shear bands. The area fraction of the LDC increased with increasing the rolling reduction, and almost all the area consisted of the LDC structure after 

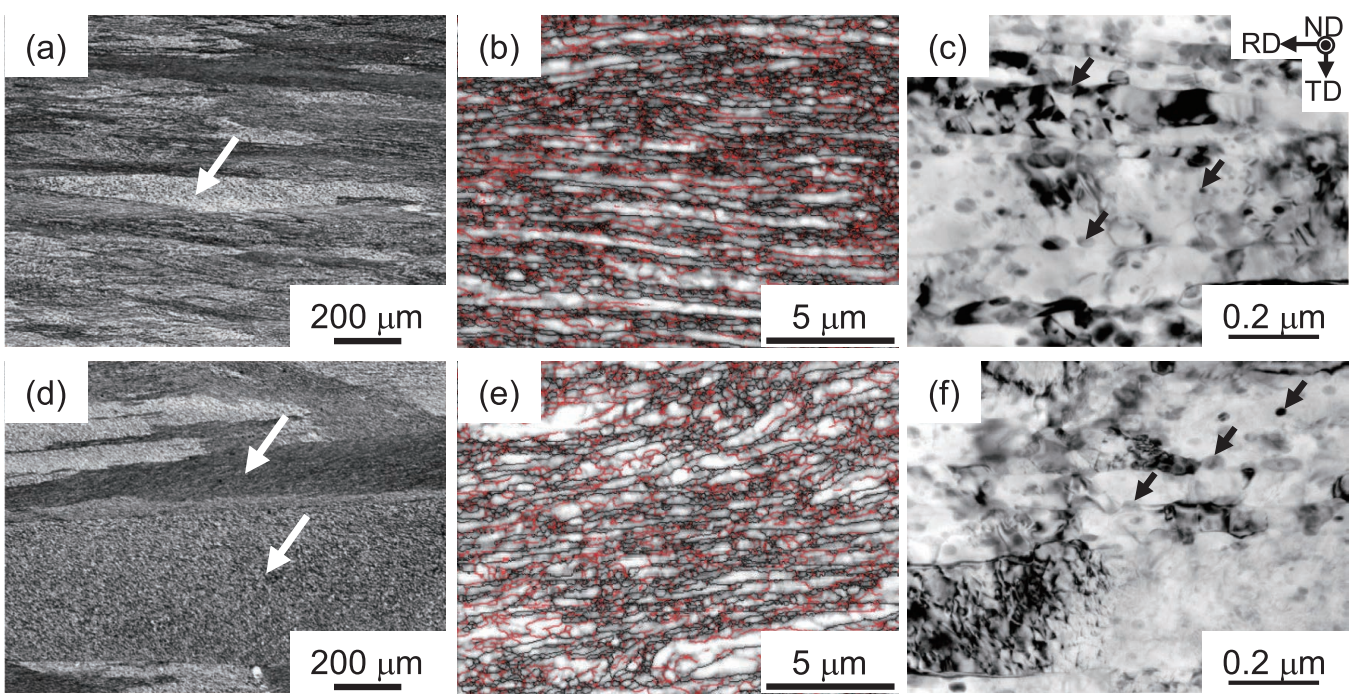

Fig. 2. Microstructures of the TF samples: steel C processed by THT 1((a)-(c)), and by THT 3((d)-(f)). The arrows in the optical micrographs ((a), (d)) denote the packet bands. The black and red lines represent high angle boundaries with a misorientation angle of $\theta \geq 15^{\circ}$ and a low angle boundary with a misorientation angle of $2 \leq \theta<15^{\circ}$, respectively, in the IQ maps ((b), (e)). The arrows in the TEM images ((c), (f)) denote the carbide particles.

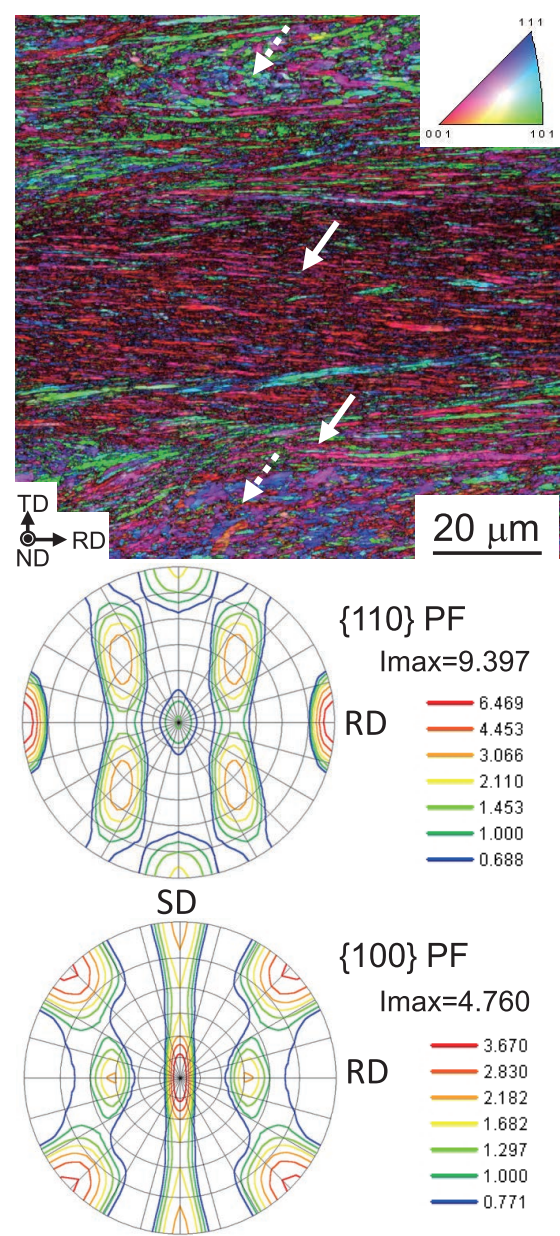

Fig. 3. IPF map for the SD on the ND plane $(\perp N D)$ in a TF sample: steel C processed by THT 1. $\{110\}$ and $\{100\}$ pole figures are also shown. The arrows indicate the ultrafine elongated grains (UFEGs) inside the packet bands.

$70 \%(\varepsilon=1.5)$ cold rolling. Furthermore, the LDC structure and the IBL structure were confirmed to have large local misorientation, and thus these structures are similar to the UFEG structure.

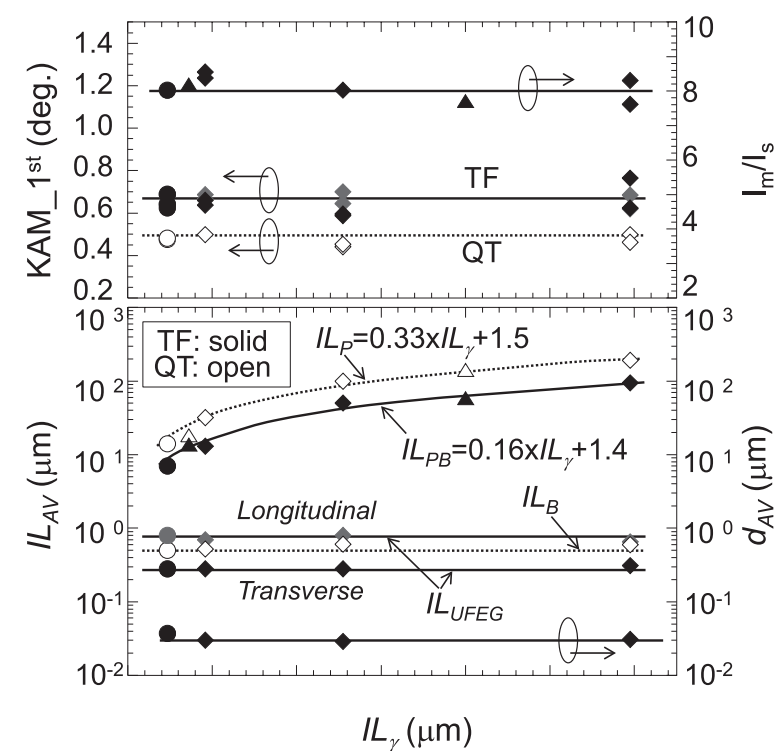

Fig. 4. Average intercept length $\left(I L_{A V}\right)$ for the UFEG structure $\left(I L_{U F E G}\right)$, packet band width $\left(I L_{P B}\right)$, average KAM value for a $1^{\text {st }}$ neighbor rank $\left(\mathrm{KAM}-{ }^{\text {st }}\right)$, and integrated intensity ratio for the (110) XRD peak on the RD plane $\left(\mathrm{I}_{\mathrm{m}} / \mathrm{I}_{\mathrm{s}}\right)$ as a function of $I L_{\gamma}$ : steel A (circle), B (triangle), and C (diamond). Grey and black symbols for the KAM- $1^{\text {st }}$ denote the data for the transverse planes (the RD planes) and longitudinal planes (the ND and SD planes), respectively. The $I L_{A V}$ for the block $\left(I L_{B}\right)$, packet $\left(I L_{P}\right)$, and KAM-1 ${ }^{\text {st }}$ for the QT samples are also shown. The average long-axis lengths of the carbide particles $\left(d_{A v}\right)$ of the TF samples are also plotted.

Figure 4 summarizes the microstructural parameters as a function of the $I L_{\gamma}$ in Table 2. The PAG structure is demonstrated to have little influence on the microstructural parameters of the UFEG structures. The integrated intensity ratio for the (110) XRD peak on the RD plane $\left(\mathrm{I}_{\mathrm{m}} / \mathrm{I}_{\mathrm{s}}\right)$, which indicates the development of the $<110>/ / \mathrm{RD}$ fiber texture, has a value within the range of 7.5 to 8.5. The kernel average misorientation (KAM) value, measured by EBSP analysis, reflects the density of the geometrically necessary 


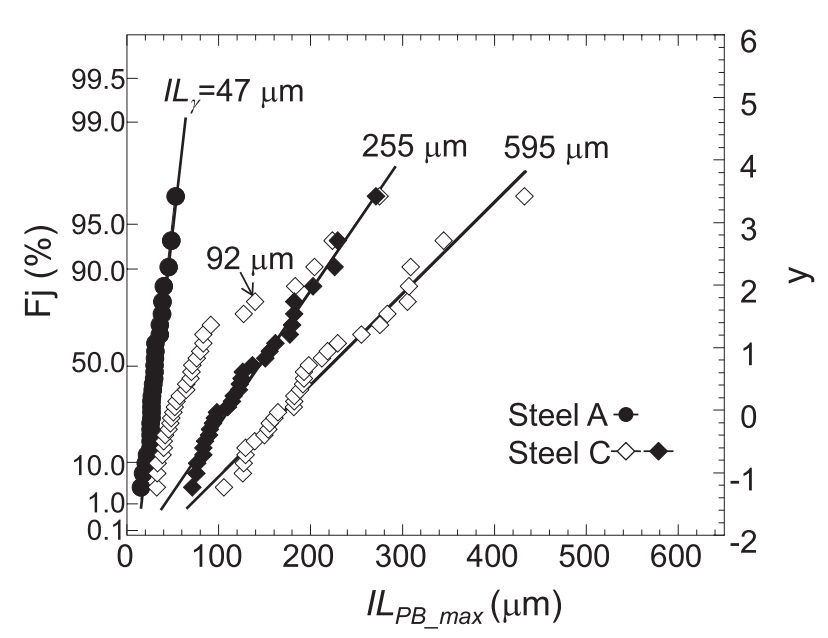

Fig. 5. Maximum intercept lengths of the packet band widths $\left(I L_{P B \_\max }\right)$ plotted on a Gumbel probability paper.

dislocations (GNDs) ${ }^{16)}$ which are associated with plastic strain gradients. ${ }^{17)}$ The average KAM value for the QT sample is approximately $0.5^{\circ}$, irrespective of the $I L_{\gamma}$, and it increases to $0.6-0.7^{\circ}$ following the WTF process. Furthermore, the average long-axis length of the carbide particles $\left(d_{A V}\right)$ was measured to be approximately $30 \mathrm{~nm}$. The $I L_{U F E G}$ in the transverse and longitudinal directions in the UFEG structures were measured to be 0.3 and $0.7 \mu \mathrm{m}$, respectively; thus, the grain size and grain shape are almost independent of the $I L_{\gamma}$. The $I L_{B}$ was measured to be $0.5-0.6 \mu \mathrm{m}$ for all the QT samples. Hence, it is reasonable to consider that the UFEG structure mainly evolves through the deformation of fine blocks in the RD. However, the packet size obviously correlates with the PAG size. From the comparison of the slopes of the regression lines, the $I L_{P B}$ is determined to be approximately half of the $I L_{P}$ at the same $I L_{\gamma}$. This demonstrates that the packet bands were formed through the extension of the packets. Therefore, it is clear that the hierarchical microstructure of the tempered martensite was inherited by the UFEG structure for the present WTF processing conditions.

The Gumbel probability plots ${ }^{18)}$ of the maximum intercept lengths of the packet band width $\left(I L_{P B} \max \right)$ are shown in Fig. 5. The reference line length was $650 \mu \mathrm{m}$, and 30 fields of view were observed by optical microscopy for each TF sample. The number of coarse packet bands decrease as the $I L_{\gamma}$ decreases. For the THT 1 conditions, steel C contains much larger packet bands than steel A. This is owed to the existence of coarse, elongated PAGs in steel C. Additionally, for each TF sample, it must be emphasized that the packet band width is much larger for the $I L_{P B_{-} \max }$ than the $I L_{P B}$. Incidentally, in the UFEG structure of steel C $\left(I L_{\gamma}=92\right.$ $\mu \mathrm{m}),{ }^{6)}$ the estimated maximum intercept lengths along the transverse and longitudinal directions were $7 \mu \mathrm{m}$ and 17 $\mu \mathrm{m}$, respectively. The packet bands therefore have a wide size distribution, in addition to the UFEG structure.

\subsection{Tensile Properties}

Figure 6 shows the tensile properties at room temperature. Here, the data for the tensile strength $\left(\sigma_{B}\right)$ of the TF samples was omitted, since the $\sigma_{y}$ was almost comparable to the $\sigma_{B}$ of each TF sample. Irrespective of the PAG size, it was observed that the TF samples exhibited discontinuous

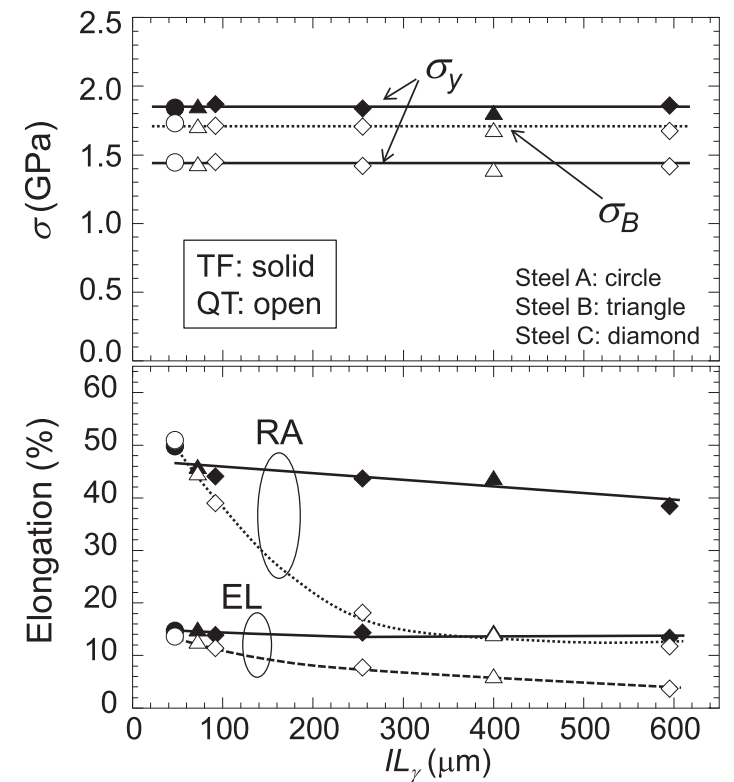

Fig. 6. Yield strength $\left(\sigma_{y}\right)$, tensile strength $\left(\sigma_{B}\right)$, total elongation (EL), and reduction of area (RA) at room temperature, as a function of $I L_{\gamma}$.

yielding behavior, while the QT samples exhibited continuous yielding behavior (the typical stress-strain curves of the TF and QT samples are reported elsewhere).,6) Similar discontinuous yielding behavior has often been observed in ultrafine grained steels. ${ }^{19-22)}$ The average $\sigma_{y}$ for the TF and QT samples were 1.85 and $1.43 \mathrm{GPa}$, respectively, and they were determined to be independent of the $I L_{\gamma}$.

In low-carbon martensitic steels, it is reported that the $\sigma_{y}$ increases as the size of the blocks and packets decrease. ${ }^{7-9)}$ Morito et al. ${ }^{8)}$ suggested that the block size is a key microstructural parameter for the $\sigma_{y}$ of the as-quenched low-carbon steel. In the present medium-carbon low-alloy steel, the packet size (in Fig. 4) has little influence on the $\sigma_{y}$. Similarly, the $\sigma_{y}$ of the TF sample is independent of the packet band size. These findings therefore indicate that the $\sigma_{y}$ of the QT and TF samples can be explained in terms of the block and UFEG structures, respectively. For the UFEG structure with a strong $<110>/ /$ RD fiber texture, the dominating parameters for the $\sigma_{y}$ are considered to be its transverse grain size, GN dislocation density, and carbide particle distribution. ${ }^{3,6)}$ The above result also supports the fact that these microstructural parameters are almost comparable among the TF samples with different PAG sizes.

Furthermore, in both the QT and TF samples, the reduction of area (RA) decreases as the $I L_{\gamma}$ increases. The RA for the QT sample demonstrates a sharp drop and decreases to approximately $15 \%$ at a $I L_{\gamma}$ of approximately $250 \mu \mathrm{m}$ or over. However, for the TF sample, the decrement in the RA is small; a high RA of $38 \%$ is maintained even with a $I L_{\gamma}$ of $600 \mu \mathrm{m}$. The average uniform elongation $\left(\varepsilon_{\mathrm{u}}\right)$ was measured to be $4-5 \%$ for the QT samples and $6-7 \%$ for the TF samples, respectively. The total elongation (EL) was therefore observed to diminish in response to the decrease in the necking elongation, for both the TF and QT samples.

Figure 7 demonstrates the variations in the $\sigma_{y}, \sigma_{F}, \varepsilon_{\mathrm{u}}$, EL, and RA of the TF samples, as a function of testing temperature and $I L_{\gamma}$. Irrespective of the $I L_{\gamma}$, the $\sigma_{y}$ increases as the testing temperature decreases from room temperature 
to $123 \mathrm{~K}$, below which it tends to increase abruptly. The increment in the $\sigma_{y}$ between room temperature and $77 \mathrm{~K}$ is approximately $0.45 \mathrm{GPa}$. Furthermore, the $\sigma_{F}$ increases as the testing temperature decreases. However, the temperature dependence of the $\sigma_{F}$ is variable, depending on the $I L_{\gamma}$. The finer the $I L_{\gamma}$, the greater the $\sigma_{F}$ is at lower temperatures. Below a temperature of $123 \mathrm{~K}$, the $\sigma_{F}$ of steel

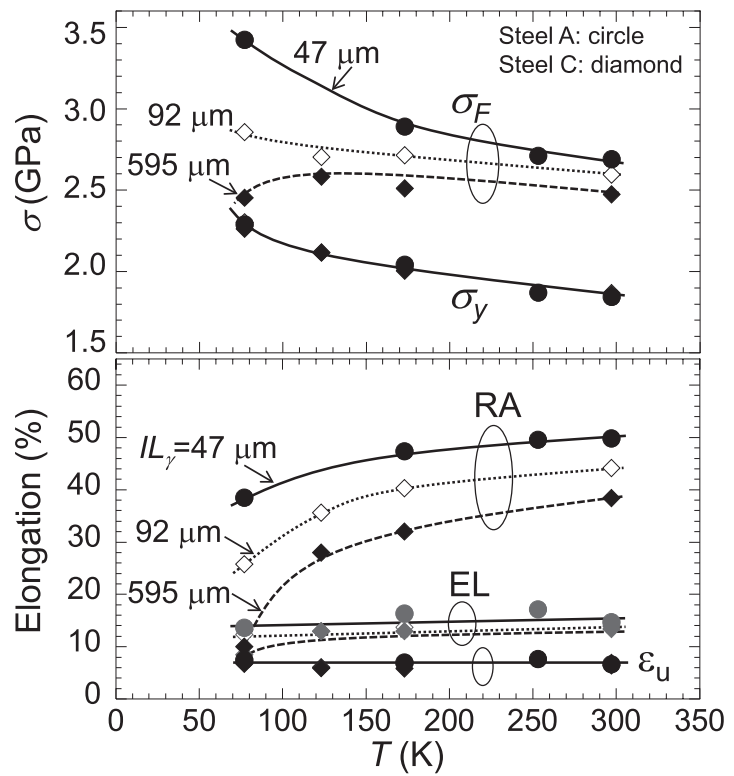

Fig. 7. Yield strength $\left(\sigma_{y}\right)$, true fracture stress $\left(\sigma_{F}\right)$, uniform elongation $\left(\varepsilon_{u}\right)$, total elongation (EL), and reduction of area (RA), as a function of $I L_{\gamma}$ and testing temperature for the TF samples.
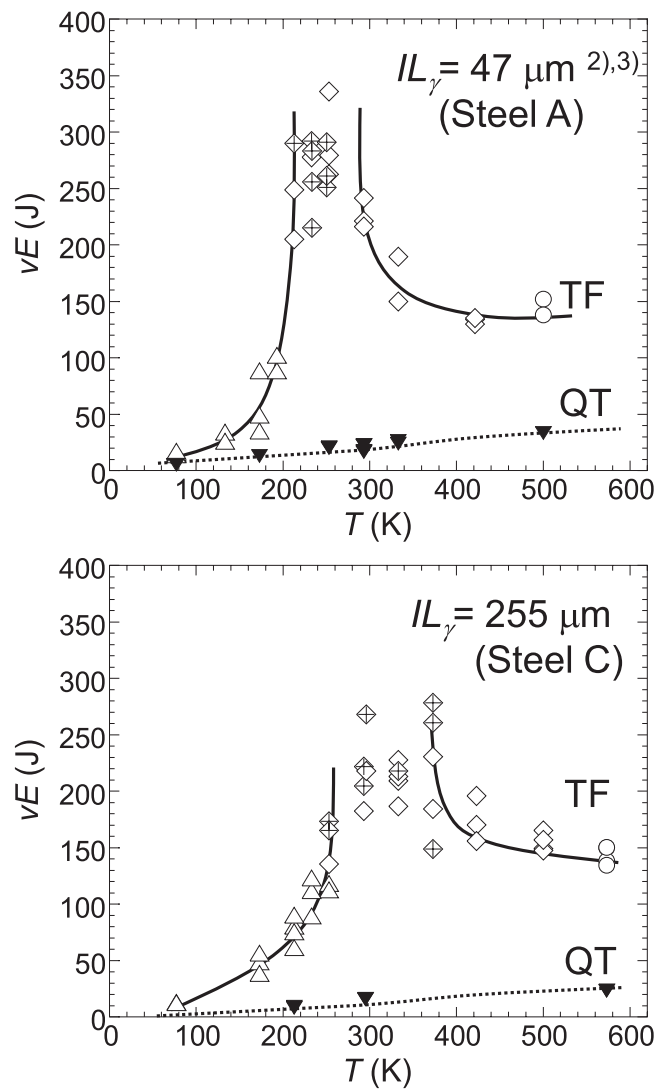

C $\left(I L_{\gamma}=595 \mu \mathrm{m}\right)$ demonstrates a slight decrease. The RA tends to decrease abruptly below a temperature of $123 \mathrm{~K}$. The drop in the RA becomes more pronounced as the $I L_{\gamma}$ increases; for steel A $\left(I L_{\gamma}=47 \mu \mathrm{m}\right)$ the average RA at 77 $\mathrm{K}$ is $39 \%$, while for steel $\mathrm{C}\left(I L_{\gamma}=595 \mu \mathrm{m}\right)$ it is $10 \%$. The EL also decreased in response to the decrease in the necking elongation; the average $\varepsilon_{\mathrm{u}}$ is approximately $6-7 \%$. This result therefore suggests that the delamination toughening may be enhanced at lower temperatures as the $I L_{\gamma}$ decreases.

\subsection{Charpy Impact Properties}

Figure 8 displays the representative fracture appearances of the Charpy V-notched impact bars for the TF samples. Figure 9 demonstrates $v E$ as a function of testing tempera-

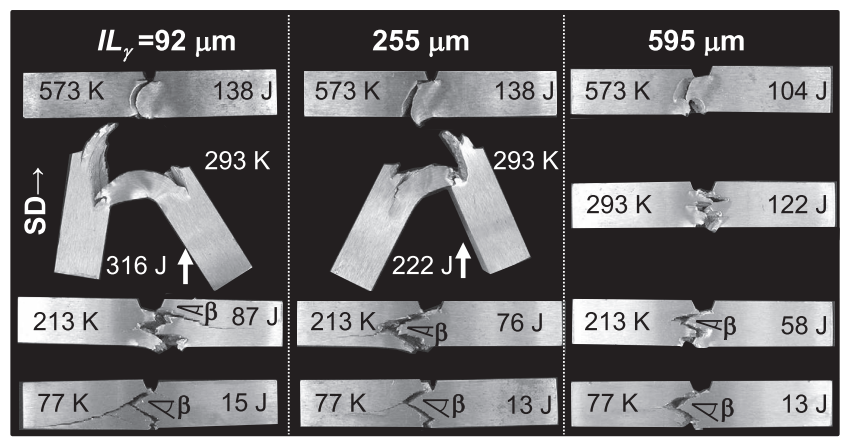

Fig. 8. Fracture appearances of the Charpy V-notched specimens following testing. The macroscopic crack branching angle $(\beta)$ was defined as the angle between the crack path and longitudinal direction (//RD) of the impact bar. The arrows indicate the specimens that did not separate into two pieces during the impact test.
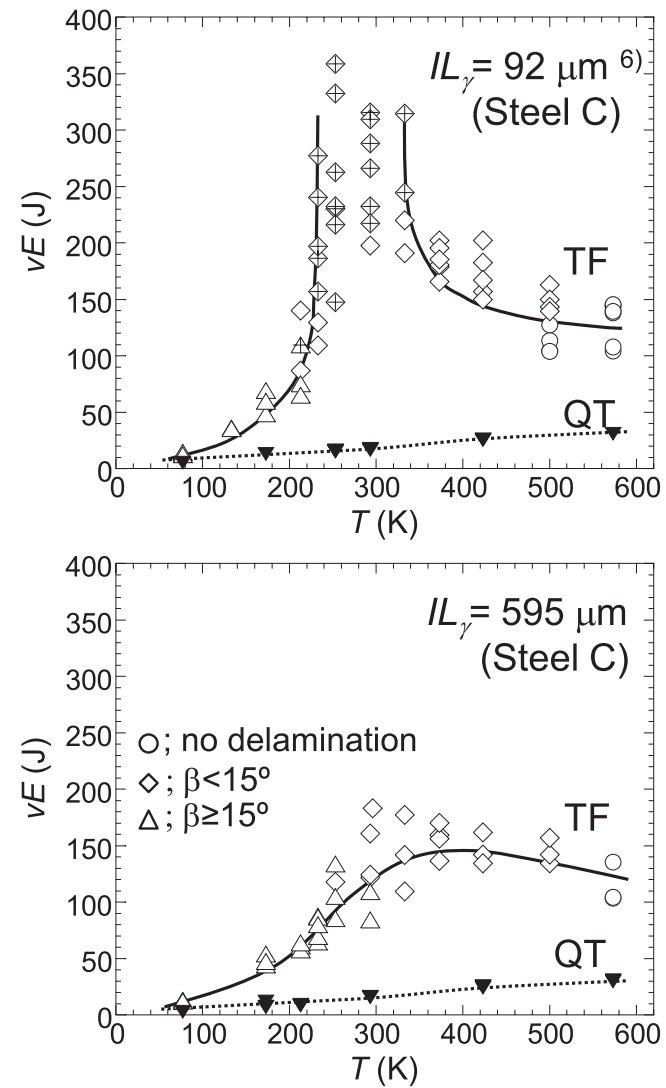

Fig. 9. Charpy V-notch absorbed energy $(v E)$ as a function of testing temperature. Data points with + indicate that the specimens did not separate into two pieces during the impact test. 
ture and the $I L_{\gamma}$. In Fig. 9, 1) the data for TF sample that demonstrated almost complete ductile fracture behavior (no delamination) at an elevated temperature is denoted by $\bigcirc$, 2) the data for the TF sample that exhibited a delamination in which the macroscopic crack branching angle $(\beta)$ of the impact specimen was below $15^{\circ 3,6)}$ is denoted by $\diamond$, and 3 ) the data for the TF sample where the $\beta$ was $15^{\circ}$ or over is denoted by $\triangle$. According to the variations in the fracture appearances of the $\mathrm{V}$-notched bars and the $v E$, the Charpy impact behavior of the TF sample can be divided into three regions; 1 ) the ductile fracture region at a temperature of approximately $500 \mathrm{~K}$ or above, 2) the delamination toughening region, and 3 ) the delamination diminishing region. The $v E$ for the QT samples is low and the PAG structure has little influence on it. By contrast, the $v E$ of the TF samples is markedly high and the inverse temperature dependence of the $v E$ tends to become significant as the $I L_{\gamma}$ decreases. In addition, fewer impact bars tended to break into two pieces as the $I L_{\gamma}$ decreased. Figure $\mathbf{1 0}$ shows the average $v E$ of the TF samples as a function of testing temperature and the $I L_{\gamma}$. The PAG size has little influence on the $v E$ at a temperature of $77 \mathrm{~K}$, where the delamination growth is markedly suppressed and the $v E$ drops to approximately $13 \mathrm{~J}$. Similarly, at temperatures of 500-573 K, the PAG size also has little influence on the average value of the $v E$ in the ductile fracture region (i.e. upper-shelf energy, $v E_{U S}$ ); the $v E_{U S}$ tends to decrease slightly as the $I L_{\gamma}$ increases. However, high $v E_{U S}$ values of 103-135 J are maintained even with a $I L_{\gamma}$ of 595 $\mu \mathrm{m}$. This tendency in the $v E_{U S}$ appears to be similar to that of the RA in Fig. 6. This suggests a correlation between the $v E_{U S}$ and RA in the TF samples that underwent ductile failure. Furthermore, within the delamination toughening region, the $v E$ is dependent on the $I L_{\gamma}$. For example, at room temperature, the $v E$ exceeds the $v E_{U S}$ for a $I L_{\gamma}$ below 400 $\mu \mathrm{m}$. When the temperature was defined as the delamination finish temperature $\left(T_{D F T}\right)$ (below this temperature, the $v E$ for the TF samples decrease to the level of its $v E_{U S}$ value, or less) the respective $T_{D F T}$ values were estimated to be approximately $213 \mathrm{~K}$ for a $I L_{\gamma}$ of $47 \mu \mathrm{m}, 233 \mathrm{~K}$ for a $I L_{\gamma}$ of $92 \mu \mathrm{m}$, $253 \mathrm{~K}$ for a $I L_{\gamma}$ of $255 \mu \mathrm{m}$, and $293 \mathrm{~K}$ for a $I L_{\gamma}$ of $595 \mu \mathrm{m}$, as shown in Fig. 9. Therefore, as the $I L_{\gamma}$ decreases, the $T_{D F T}$ is lowered, leading to a higher $v E$ at lower temperatures. For

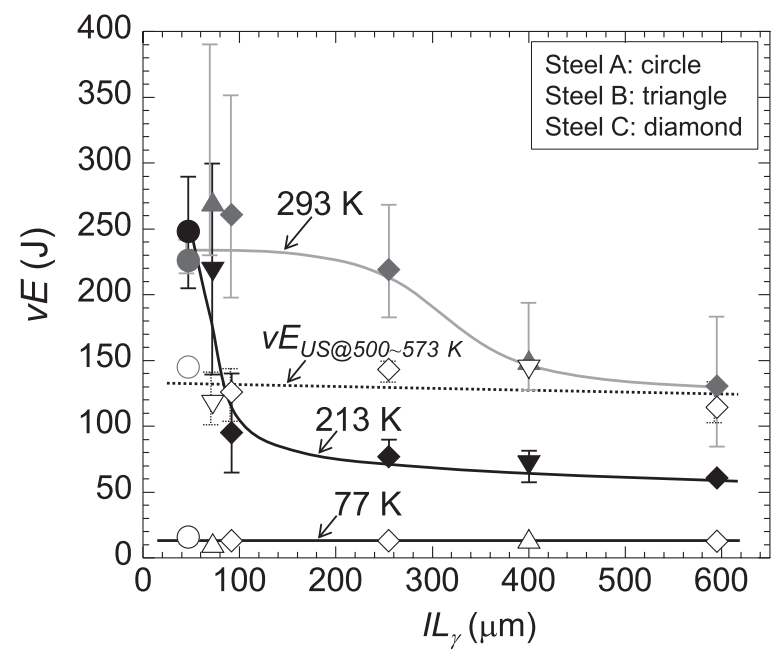

Fig. 10. Average $v E$ of the TF samples as a function of $I L_{\gamma}$ and testing temperature. example, at $213 \mathrm{~K}$, there is a remarkable difference in the $v E$ depending on the $I L_{\gamma}$.

\section{Discussion}

Ausformed steels, ${ }^{23,24)}$ laminates, ${ }^{25)}$ and laminated composites $^{26)}$ were reported to exhibit similar delaminations as a result of their anisotropic microstructures. When weak interfaces and/or weak planes are present parallel to the longitudinal direction $(/ / \mathrm{RD})$ of the impact test bar, the interaction between the weak interfaces (and/or weak planes) and the tensile stress along the $\mathrm{SD}\left(\sigma_{t / / S D}\right)$ can cause delaminations. ${ }^{23-26)}$ The $\sigma_{t}$ is generated by the localized plastic constrain at the notch and/or the crack tip, and it is proportional to the $\sigma_{y}$. If the Tresca yield criterion is assumed in the process zone within the plastically yielding region of the notch root, the $\sigma_{t / / R D}$ and $\sigma_{t / / S D}$ in the process zone can be approximated as $2.6 \times \sigma_{y}$ and $1.6 \times \sigma_{y},{ }^{5)}$ respectively. Once the notch and/or crack tip become blunt from the occurrence of delamination, crack re-initiation is necessary in order to fracture the material. ${ }^{25)}$ In the crack-arrestor delamination, this occurs under conditions of nearly uniaxial tension, which is an unfavorable cleavage. ${ }^{25)}$ The stress fielding effect from the formation of microcracks along the $\mathrm{RD}$ can also reduce the driving force for fracture. ${ }^{27)}$ As a result, the $v E$ is enhanced through the occurrence of crack arrester-type delamination.

Figure 11 displays the representative fracture surfaces of the TF samples that were tested at a temperature of $293 \mathrm{~K}$, where the marked difference in the delamination toughening was observed. In all the TF samples, "terraces" and "steps" are formed. The terraces correspond to delamination planes and are generally parallel to the RD (Figs. 11(a)-11(c)). This stepwise crack propagation is a common feature in steels which exhibit similar delamination toughening. ${ }^{23,24)}$ Furthermore, in all the TF samples, it is observed that the fracture mode on the terraces primarily occurred by a quasicleavage, whereas a ductile fracture mode (with fine dimple patterns) occurred on the steps (Figs. 11(d)-11(f)). Narrow, elongated quasi-cleavage facets that are aligned in the RD on the terraces appear to correspond to the morphology of the UFEG structures (Figs. 11(d)-11(f)). Therefore, the PAG size has little influence on the microscopic modes of fracture on the terraces and steps. However, it should be noted that the terraces and steps were observed to increase in size as the PAG size increased (Figs. 11(a)-11(c)). In steel A $\left(I L_{\gamma}=47 \mu \mathrm{m}\right)$, the presence of many fine steps confirms the extensive local plastic flow during delamination (Fig. 11(a)), generating a higher $v E$. Although coarse steps are partially observed in steel $\mathrm{C}\left(I L_{\gamma}=92 \mu \mathrm{m}\right)$ (as indicated by the arrow in Fig. 11(b)), the macroscopic mode of fracture of steel C is similar to that of steel A. By contrast, the macroscopic mode of fracture in steel $\mathrm{C}\left(I L_{\gamma}=595 \mu \mathrm{m}\right)$ is characterized by coarse steps and terraces (Fig. 11(c)). These coarse steps suggest that transverse crack propagation may be facilitated rather than the delamination growth along the $\mathrm{RD}$, therefore suppressing the delamination toughening (Fig. 9).

Figure 12 displays the representative fracture surfaces of the TF samples that were tested at $213 \mathrm{~K}$, where the change in the $v E$ became more significant in relation to the $T_{D F T}$. Stepwise crack propagations are also observed in all the TF 

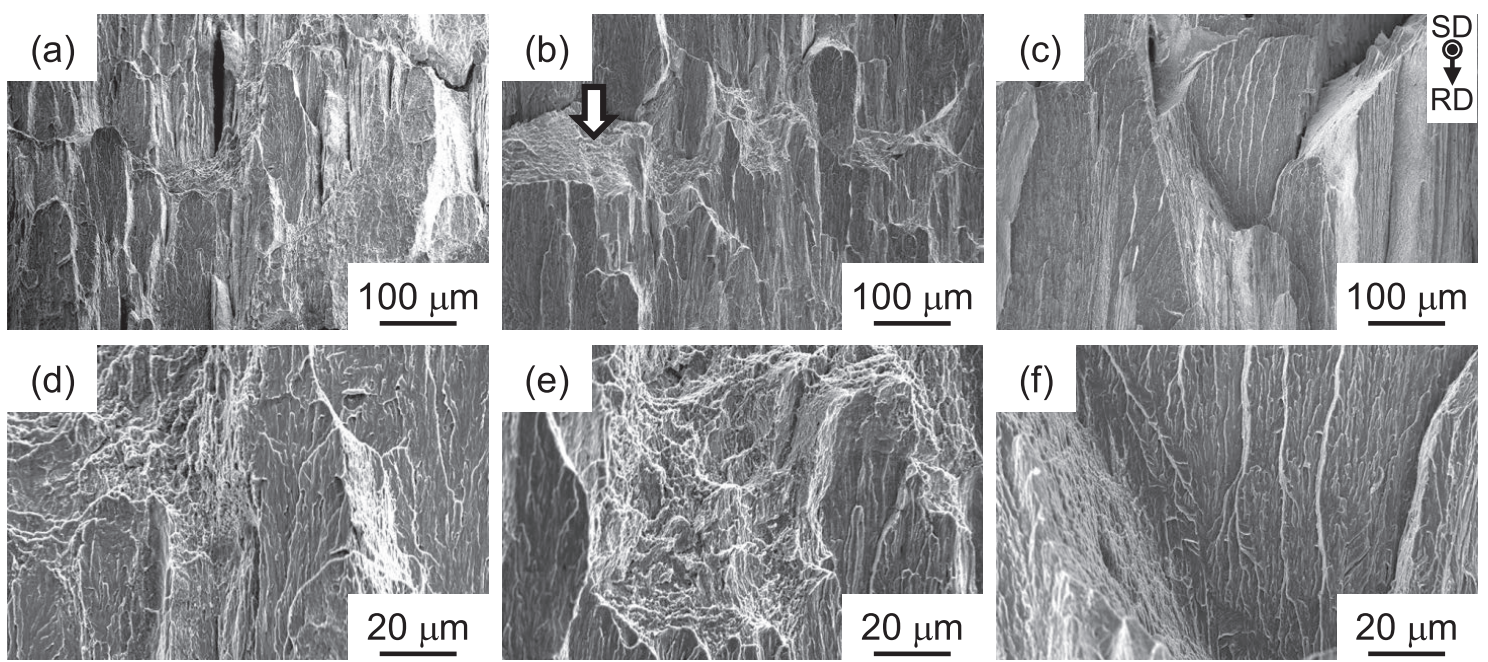

Fig. 11. SEM fractographs demonstrating the fracture surfaces of the TF samples which were impact tested at $293 \mathrm{~K}$ : $I L_{\gamma}=47 \mu \mathrm{m}((\mathrm{a}),(\mathrm{d})), 92 \mu \mathrm{m}((\mathrm{b}),(\mathrm{e}))$, and $595 \mu \mathrm{m}$ ((c), (f)). The arrow indicates a step.
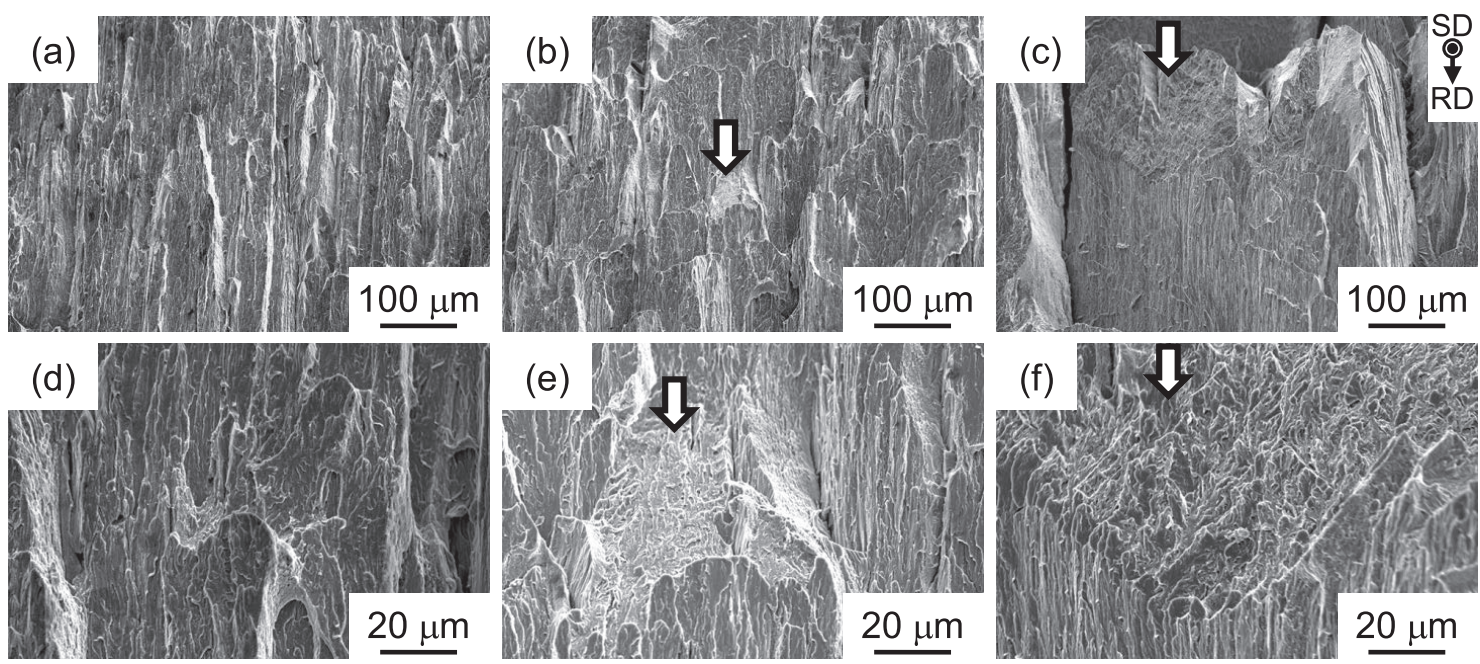

Fig. 12. SEM fractographs demonstrating the fracture surfaces of the TF samples that were impact tested at $213 \mathrm{~K}$ : $I L_{\gamma}=47 \mu \mathrm{m}$ ((a), (d)), $92 \mu \mathrm{m}((\mathrm{b}),(\mathrm{e}))$, and $595 \mu \mathrm{m}((\mathrm{c}),(\mathrm{f}))$. The arrows indicate transverse quasi-cleavage cracks.

samples. However, in steel $\mathrm{C}$ which was tested below its $T_{D F T}$, the terraces are linked with transverse quasi-cleavage cracks in some parts (as indicated by arrows in Figs. 12(e) and 12(f)). The size and fraction of the transverse cleavage fracture area was observed to increase as the PAG size increased. Hence, the occurrence of transverse cleavage fracture may result in a lower $v E$. This also indicates that microstructural inhomogeneity (which results in transverse cracking) needs to be minimized. ${ }^{3)}$

Figure 13 displays the representative optical micrographs which demonstrate the relationship between the microstructure and the crack propagation path for the TF samples. It appears that deflection of the cracks and delamination occurs in relation to the packet bands. The delamination cracks also appear to propagate along the boundaries of the packet bands. This is more apparent at coarse packet bands. The stepwise crack propagations can be related to the packet bands. Hence, the length of the steps (including transverse cleavage cracks) becomes shorter as the width of the packet bands become shorter.

When we consider the occurrence of delamination for the TF steel with an UFEG structure with a strong $<110>/ /$ $\mathrm{RD}$ fiber texture, the spatial distribution of weak sites, such as $\{100\}$ cleavage planes, and grain boundaries (involving carbide particles) is important. ${ }^{5)}$ In the $<110>/ / \mathrm{RD}$ fiber texture, many $\{100\}$ cleavage planes are distributed both on the SD planes $(\perp \mathrm{SD})$ and on the $45^{\circ}$ planes (which are inclined at an angle of $45^{\circ}$ to the RD), as indicated in Fig. 3. The boundaries of the UFEGs are crystallographic discontinuities in the $\{100\}$ cleavage planes, and hence an UFEG can be considered as an effective grain for cleavage fracture. The size of the quasi-cleavage facet on the terraces appears to correspond to the size of the UFEGs (Fig. 11). It is wellknown that the coherence length of the $\{100\}$ cleavage planes corresponds to the effective grain size $\left(D_{\text {eff }}\right)$, and that the cleavage fracture stress $\left(\sigma_{\mathrm{c}}\right)$ is proportional to the inverse square root of the $D_{\text {eff. }}{ }^{12)}$ The $D_{\text {eff }}$ for the UFEGs is shorter in the $45^{\circ}$ direction than in the RD as a result of the elongated grain shape. Thus, the cleavage fracture stress along the $45^{\circ}$ direction $\left(\sigma_{c / / 45^{\circ}}\right)$ is greater than the cleavage fracture stress along the $\mathrm{SD}\left(\sigma_{c / / S D}\right)$. Similarly, the intergranular fracture stress in the SD is low, as a result of the elongated grain 

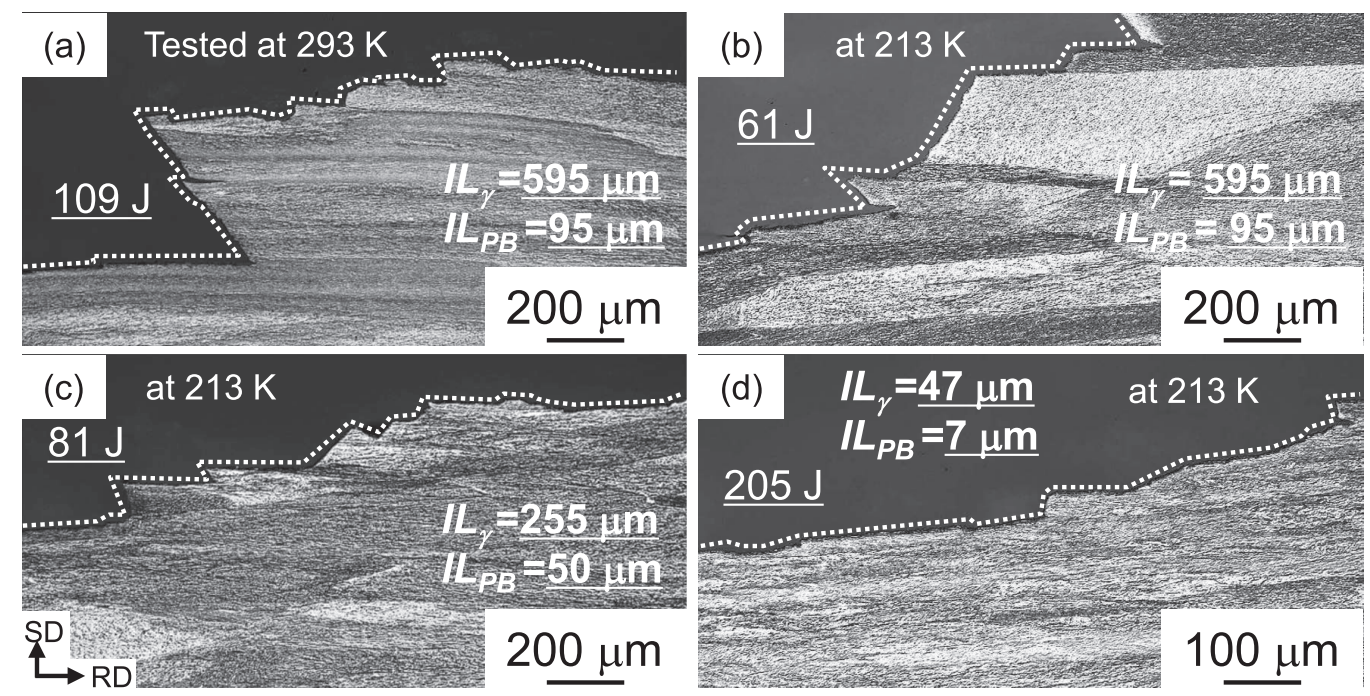

Fig. 13. Optical micrographs demonstrating the relationship between the microstructure and the crack propagation paths for the TF samples that were impact tested.

shape and the good grain boundary continuity along the RD. ${ }^{28,29)}$ Therefore, on the basis of the Yoffee diagram for the UFEG structure, this provides the necessary conditions to cause the delamination along the $\mathrm{RD}^{3,4,6)}$ Since both the $\sigma_{c / 45^{\circ}}$ and the $\sigma_{y}$ can be improved as the transverse grain size decreases, the transverse grain size of the UFEG is a key factor in controlling the strength and toughness of the TF steel. $^{3,4,6)}$ In the present TF samples, the transverse grain size of the UFEG structures is relatively consistent regardless of the $I L_{\gamma}$ (Fig. 4). The $\sigma_{y}$ is also independent of the $I L_{\gamma}$ (Figs. $6,7)$. Hence, the occurrence condition for the delamination is considered to be almost comparable.

Additionally, in order to enhance the delamination toughening at lower temperatures, higher toughness and ductility of the RD plane $(\perp R D)$ in the UFEG structure was considered to be a sufficient condition. This is because ductile crack propagation in the transverse direction may suppress the occurrence of delamination (Fig. 11). Additionally, the ductile cracks, which are initiated during delamination at lower temperatures, may also act as brittle crack initiation sites. As demonstrated in Figs. 5 and 6 , the $\sigma_{F}$ and RA for the TF sample decreased with increasing the $I L_{\gamma}$. An effective mechanism for improving the the $\sigma_{F}$ and RA is to reduce the volume fraction and size of carbide particles; ${ }^{6}$ ) however, there was no significant difference in the carbide particle distribution among the present TF samples (Fig. 4). Here, it should be noted that the crystallographic orientation and geometric arrangement of the UFEGs are relatively similar within a packet band (Fig. 3); the packet band may demonstrate relatively good continuity of the $\{100\}$ cleavage planes and weak UFEG boundaries (including carbide particles). Hence, cracks can penetrate the packet band without any significant deflection (Fig. 13), and the packet bands may act as an elongated grain.

It has been reported that the block size governs the $D_{\text {eff }}$ for cleavage in lath martensitic steels; cleavage cracks were observed to deflect or blunt at the boundaries between blocks with different Bain axes. ${ }^{13)}$ The QT samples had a fine block structure with a $I L_{B}$ of $0.5-0.6 \mu \mathrm{m}$ (Figs. 1, 4) and their $\sigma_{c}$ was suggested to be comparable to the $\sigma_{c / / 45^{\circ}}$ of the TF samples. ${ }^{3,5,6)}$ However, the QT samples exhibited a quasi-cleavage fracture even at room temperature. This was owing to the ultrahigh $\sigma_{y}$, and therefore the $v E$ of the QT samples was low (Fig. 9). The low $v E$ may be responsible for the isotropic properties of the QT samples; once cracks initiate in the QT sample (with an isotropic microstructure), cracks can easily propagate along the SD, leading to the failure of the sample. Therefore, it is usually difficult to suppress the crack initiation in ultra-high-strength steel. Our strategy to enhance the toughness of ultra-high-strength steels is to arrest the propagation of main cracks along the transverse directions in the hierarchical, anisotropic, and ultrafine grain structure designed to be fail-safe, in addition to suppressing the crack initiation. From this perspective, a packet band may be considered to be an effective grain in order to control the delamination toughening in a TF steel with an UFEG structure. The reduction in the width of the packet bands can lead to the suppression of the transverse crack propagation, leading to the enhanced delamination. Since the packet band size, in addition to the packet size, correlates to the PAG size (Fig. 4), the refinement of the PAG size is an effective mechanism for this.

Therefore, these findings demonstrate that the PAG size has little influence on the strength of the present WTF steel. However, the effect of warm tempforming on the tensile ductility and toughness can be improved by decreasing the PAG size.

\section{Conclusions}

The influence of the PAG structure on the microstructure, tensile and Charpy impact properties was investigated for $0.4 \% \mathrm{C}-2 \% \mathrm{Si}-1 \% \mathrm{Cr}-1 \% \mathrm{Mo}$ steels that were processed via WTF using multi-pass caliber rolling with a rolling reduction of $78 \%$ at a temperature of $773 \mathrm{~K}$. The results obtained are as follows;

(1) The TF steels had hierarchical microstructures consisting of packet bands and UFEGs with strong $<110>/ /$ RD fiber textures. The packet bands and UFEGs mainly evolved through the extension of the packets and blocks in tempered martensitic structures, respectively.

(2) The PAG structure had little influence on the trans- 
verse grain size, grain shape, $<110>/ / R D$ fiber texture, and the carbide particle distribution in the UFEG structure. However, the size of the packet bands correlated with the PAG size.

(3) The $\sigma_{y}$ of the TF steel was independent of the PAG size, while the tensile ductility improved as the PAG size decreased, especially at lower temperatures.

(4) As the PAG size decreased, the inverse temperature dependence of toughness, resulting from delamination, became significant at lower temperatures, leading to a higher $v E$.

(5) It was considered that the reduction in the width of the packet bands could result in the suppression of the transverse crack propagation, leading to the enhanced delamination. The refinement in the PAG size was effective for this.

\section{Acknowledgements}

The authors thank Mr. Kuroda and Mr. Taniuchi for materials processing with caliber-rolling and Ms. Hirota for her assistance with the microstructural observation. The study was partly supported by grants from the JFE 21 st Century Foundation and it was supported by the Japan Science and Technology Agency (JST) under Collaborative Research Based on Industrial Demand "Heterogeneous Structure Control: Towards Innovative Development of Metallic Structural Materials".

\section{REFERENCES}

1) I. Tamura: Bull. Jpn. Inst. Met., 2 (1963), 426.

2) Y. Kimura, T. Inoue, F. Yin and K. Tsuzaki: Science, 320 (2008), 1057
3) Y. Kimura and T. Inoue: Metall. Mater. Trans. A, 44A (2013), 560.

4) Y. Kimura, T. Inoue, F. Y in and K. Tsuzaki: ISIJ Int., 50 (2010), 152.

5) T. Inoue and Y. Kimura: J. Mater. Sci., 48 (2013), 4766.

6) Y. Kimura and T. Inoue: Tetsu-to-Hagané, 100 (2014), 1104

7) T. Swarr and G. Krauss: Metall. Trans. A, 7A (1976), 41.

8) S. Morito, H. Saito, T. Ogawa, T. Furuhara and T. Maki: ISIJ Int., 45 (2005), 91.

9) C. Zhang, Q. Wang, J. Ren, R. Li, M. Wang, F. Zhang and K. Sun: Mater. Sci. Eng. A, 534 (2012), 339.

10) S. Morito, H. Yoshida, T. Maki and X. Huang: Mater. Sci. Eng. A, 438-440 (2006), 237.

11) S. Masuda, T. Inoue, H. Mimura and Y. Okamura: Proc. Int. Symp. on Toward Improved Ductility and Toughness, ISIJ, Tokyo and Jpn. Inst. Met., Sendai, Japan, (1971), 47.

12) J. W. Morris, Jr.: ISIJ Int., 48 (2008), 1063.

13) J. W. Morris, Jr., C. Kinney, K. Pytlewski and Y. Adachi: Sci. Technol. Adv. Mater., 14 (2013), 014208.

14) T. Maki, K. Akasaka, K. Okuno and I. Tamura: Tetsu-to-Hagané, 66 (1980), 1659.

15) R. Ueji, N. Tsuji, Y. Minamino and Y. Koizumi: Sci. Technol. Adv. Mater., 5 (2004), 153

16) M. F. Ashby: Philos. Mag., 21 (1970), 399.

17) M. Calcagnotto, D. Ponge, E. Demir and D. Raabe: Mater. Sci. Eng. A, 527 (2010), 2738

18) Y. Murakami: Metal Fatigue: Effect of Small Defects and Nonmetallic Inclusions, Yokendo Ltd., Tokyo, (1993), 118.

19) S. Takaki, K. Kawasaki and Y. Kimura: J. Mater. Process. Technol., 117 (2001), 359.

20) A. Ohmori, S. Torizuka and K. Nagai: ISIJ Int., 44 (2004), 1063.

21) Y. Tomota, A. Narui and N. Tsuchida: ISIJ Int., 48 (2008), 1107.

22) N. Tsuji, N. Kamikawa, R. Ueji, N. Takata, H. Koyama and D. Terada: ISIJ Int., 48 (2008), 1114.

23) A. J. McEvily, Jr. and R. H. Bush: Trans. ASM, 55 (1962), 654.

24) C. M. Yen and C. A. Stickels: Metall. Trans., 1 (1970), 3037.

$25)$ J. D. Embury, N. J. Petch, A. E. Wraith and E. S. Wright: Trans. Metall. Soc. AIME, 239 (1967), 114.

26) D. W. Kum, T. Oyama, J. Wadsworth and O. D. Sherby: J. Mech. Phys., 31 (1983), 173

27) T. Inoue and Y. Kimura: Trans. JSME, 79 (2013), 1226.

28) M. Jafari, Y. Kimura and K. Tsuzaki: Metall. Mater. Trans. A, 43A (2012), 2453.

29) Y. Nie, Y. Kimura, T. Inoue, F. Yin, E. Akiyama and K. Tsuzaki: Metall. Mater. Trans. A, 43A (2012), 1670. 